\title{
Width of sulcus and thickness of gyrus in patients with cerebral atherosclerosis: a new tool for the prevention of vascular cognitive impairment
}

\author{
Luciana Santos Ramalho' \\ D Luciano Alves Matias da Silveira² \\ Bárbara Cecílio Fonseca ${ }^{3}$ \\ José Eduardo Reis Félix ${ }^{4}$ \\ Lourimar José Morais ${ }^{5}$ \\ Maria Helena Soares ${ }^{6}$ \\ Mara Lúcia Fonseca Ferraz ${ }^{7}$ \\ Vicente de Paula Antunes Teixeira ${ }^{8}$ \\ Sanívia Aparecida Lima Pereira ${ }^{9}$

\begin{abstract}
1. PhD in Pathology, Student of Postgraduate Course Health Sciences, Universidade Federal do Triângulo Mineiro (UFTM), Uberaba (MG), Brasil. 2. MS in Pathology, Anesthesiologist, Professor of Anesthesiology, Department of Surgery, Universidade Federal do Triângulo Mineiro (UFTM), Uberaba (MG), Brasil. 3. Medical Student at UFTM, Scientific Initiation Grant from UFTM (BIC/Fapemig), Uberaba (MG), Brasil. 4. Department of Radiology, Universidade Federal do Triângulo Mineiro (UFTM), Uberaba (MG), Brasil. 5. MS in Pathology, Universidade Federal do Triângulo Mineiro (UFTM), Uberaba (MG), Brasil. 6. MS in Pathology, Universidade Federal do Triângulo Mineiro (UFTM), Uberaba (MG), Brasil.

7. PhD in Pathology, Professor of Postgraduate Course Health Sciences, Universidade Federal do Triângulo Mineiro (UFTM), Uberaba (MG), Brasil. 8. Pathologist, Professor of General Pathology, Institute of Biological and Natural Sciences, Universidade Federal do Triângulo Mineiro (UFTM), Uberaba (MG), Brasil. 9. PhD in Pathology, Professor of Postgraduate Course Health Sciences, Universidade
\end{abstract} \\ Federal do Triângulo Mineiro (UFTM), Uberaba (MG), Brasil.
}

http://dx.doi.org/10.1590/1806-9282.64.08.684

\section{SUMMARY}

BACKGROUND AND PURPOSE: Cerebral atherosclerosis is the main cause of lesions that contribute to vascular cognitive impairment and vascular dementia, followed by arteriosclerosis of small vessels and cerebral amyloid angiopathy. The purpose of this study was to compare the post-mortem radiological alterations of autopsied adults with the macroscopic alterations in the posterior region of these brains in order to establish a relationship between the two forms of analysis and to discuss the relevance of the prevention of vascular cognitive impairment in patients with encephalic atherosclerosis.

MATERIALS AND METHODS: Thirteen brains were analysed macroscopically to assess the degree of atherosclerosis of the basilar and the posterior cerebral arteries. The patients were autopsied in the Subject of General Pathology at General Hospital of Triângulo Mineiro Federal University in Uberaba, state of Minas Gerais, Brazil. The qualitative analysis of atherosclerosis was performed with classification into mild, moderate or severe. In the posterior region of the brains, width of sulcus and thickness of gyrus were measured by macroscopic analysis and by tomographic analysis.

RESULTS AND CONCLUSIONS: There was a decrease in calcarine sulcus width and an increase in medial temporal occipital gyrus thickness in patients with a higher degree of atherosclerosis, macroscopically and in tomography, respectively. Low oxygenation caused by atherosclerosis probably leads to an encephalic parenchyma inflammation that causes microglial cells hypertrophy provoking increase in the gyrus thickness and decrease in the sulcus width, as observed in the present study.

KEYWORDS: Intracranial arteriosclerosis. Cognitive dysfunction. Cerebrovascular disorders. Cognition disorders. Tomography, X-ray computed.

Isantosramalho@yahoo.com.br bacecilio@live.com; felix@anomati.net lourimar_morais@yahoo.com.br mhmais@hotmail.com mara@patge.uftm.edu.br vicente@patge.uftm.edu.br sanivia.pereira@uniube.br 


\section{BACKGROUND}

Cerebral atherosclerosis is the main cause of lesions that contribute to vascular cognitive impairment (VCI) and vascular dementia, followed by arteriosclerosis of small vessels and cerebral amyloid angiopathy ${ }^{1}$. Autopsy studies have already identified atherosclerotic plaques in the vertebrobasilar system in $50 \%$ of the cadavers examined, and most patients with atherosclerotic plaques in the basilar artery had severe plaques ${ }^{2}$. VCI encompasses discrete cognitive deficit, which does not necessarily lead to dementia ${ }^{3}$. There is suspicion of VCI when there is atherosclerosis, arteriolosclerosis, amyloid angiopathy, focal or diffuse ischemic changes, or haemorrhagic foci ${ }^{4}$. There are currently no tomographic diagnostic criteria for VCI and there is a need to establish evidence to base these criteria for assessing the contribution of cerebrovascular disease for $\mathrm{VCI}^{5}$.
There are studies that emphasize the importance of in vivo imaging studies of ischemic brain lesions such as PET scan, magnetic resonance imaging (MRI), CT and computed angiotomography (CAT) $)^{6,7}$ and post-mortem $\mathrm{CT}^{8}$. Post mortem CT was introduced about 14 years ago and several researchers have demonstrated its usefulness primarily in cases of post-traumatic bone injury ${ }^{9,10}$, and also in cases of vascular injury with the aid of $\mathrm{CAT}^{11,12}$.

To date, there are no studies to identify radiological changes in VCI of patients with cerebral atherosclerosis, so the present study emphasizes the importance of imaging in the identification of pathological processes, contributing to the prevention of diseases such as VCI. It is probable that patients with atherosclerosis in arteries that irrigate the posterior portion of the brain, such as the basilar and the posterior cerebral arteries, present changes

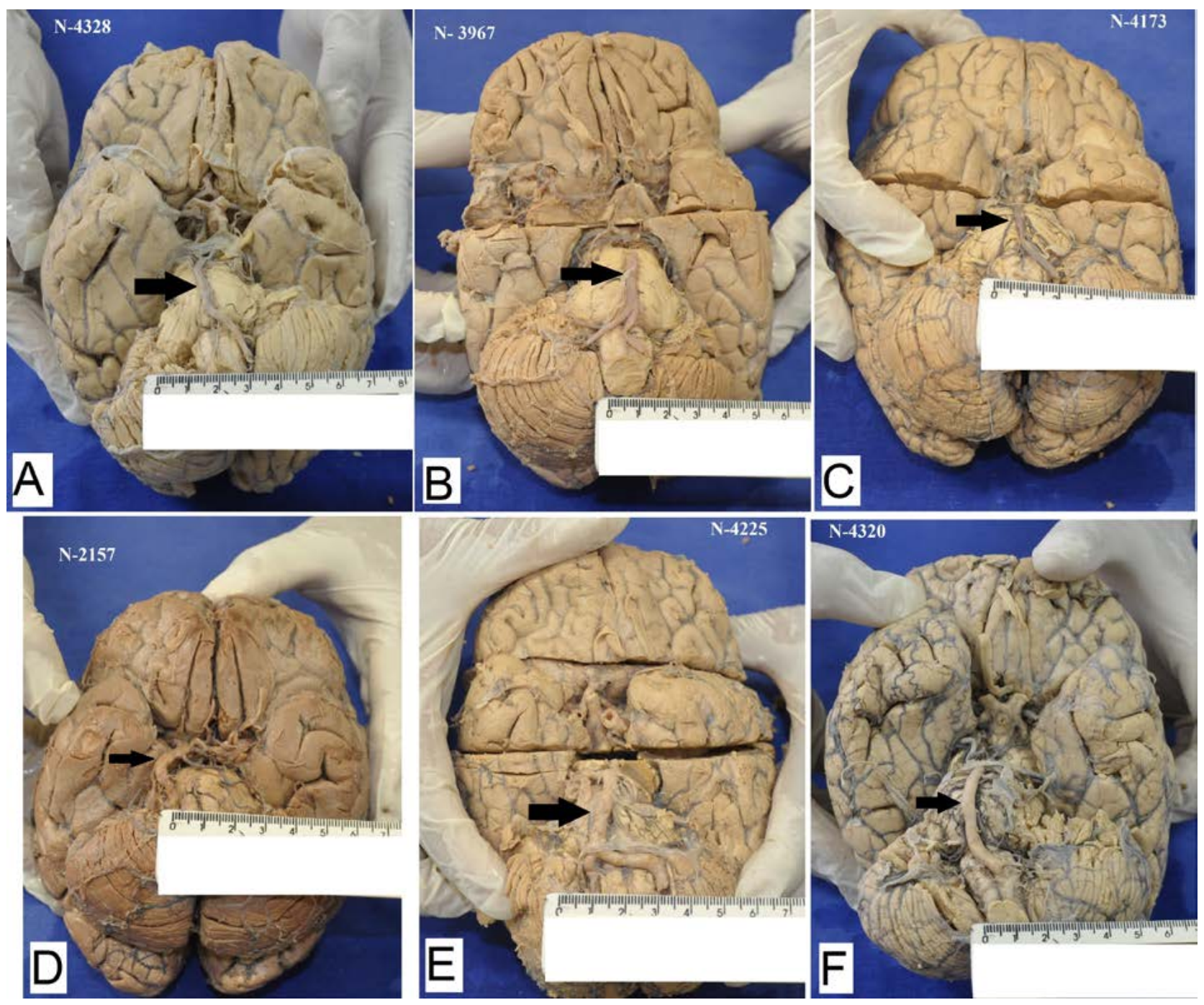

FIGURE 1. Microscopical analysis. The basilar arteries were evaluated according to the presence of atheromatous plaques and aneurysms. The black narrow point the basilar arteries. A and B: mild atherosclerosis, C: moderate atherosclerosis, D, E and F: severe atherosclerosis with a mild aneurysm. 


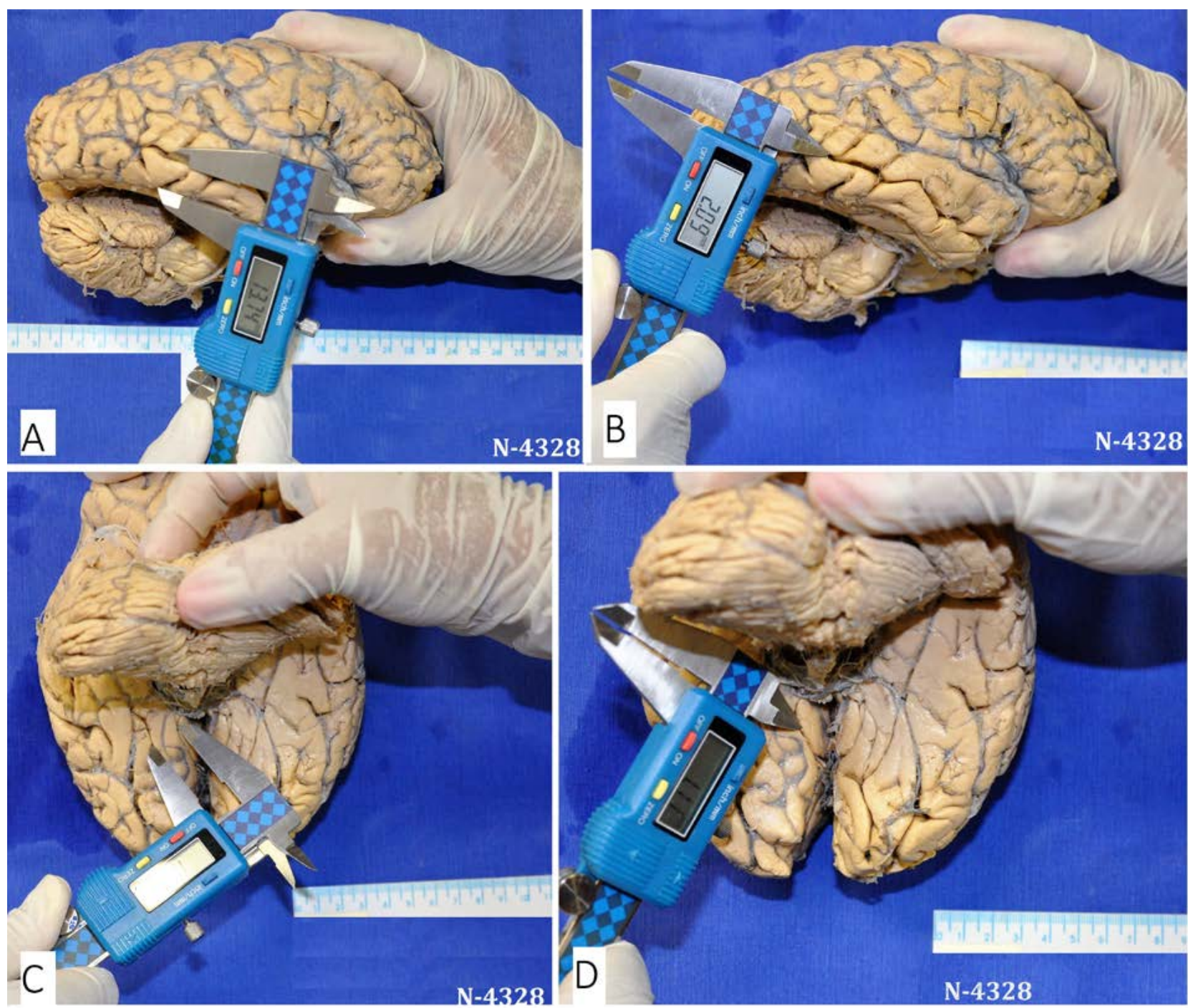

FIGURE 2. Macroscopic location of the sulcus and gyrus macroscopically measured with caliper. Measurement of the transverse thickness of the right inferior temporal gyrus in the posterior medial portion of the gyrus (A). Measurement of the width of the right inferior temporal sulcus just above the measurement site of the right inferior temporal gyrus (B). Measurement of the transverse thickness of the right medial temporal occipital gyrus in the central portion of the gyrus (C). Measurement of the width of the right calcarine sulcus laterally to the measurement site of the calcarine sulcus (D).

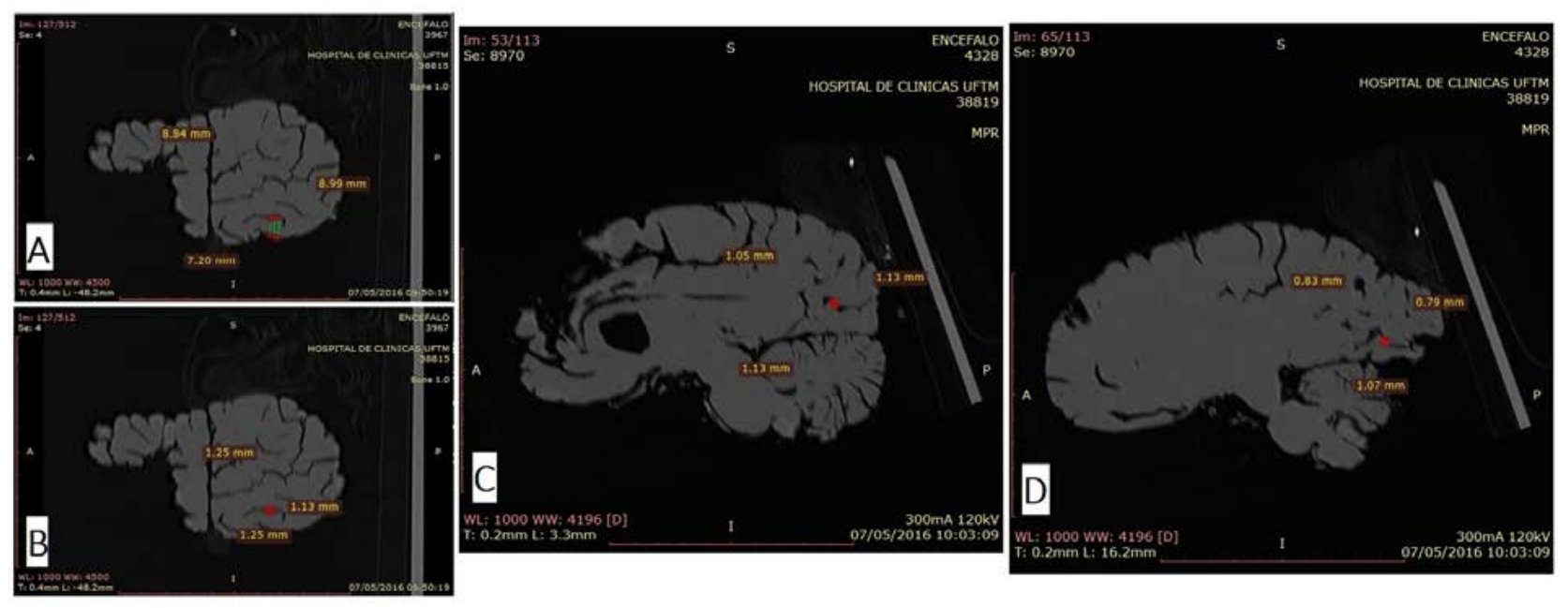

FIGURE 3. Sagittal sections of encephala. A: Right ITG measure. B: Left ITS measure. C: Right CS measure D: Left CS measure. 
in the encephalic mass such as oedema or hypotrophy due to insufficient irrigation in this region.

\section{AIMS}

Thus, this study compared the post-mortem radiological alterations of autopsied adults with the macroscopic alterations in the posterior region of these brains in order to establish a relationship between the two forms of analysis and to discuss the relevance of the prevention of $\mathrm{VCI}$ in patients with encephalic atherosclerosis.

\section{METHODS}

\section{Selection of patients}

The study was performed with 13 patients autopsied in the Subject of General Pathology at General Hospital of Triângulo Mineiro Federal University (GHUFTM) in Uberaba, state of Minas Gerais, Brazil. We evaluated 3000 autopsy protocols from 1963 to 2016. Patients were selected by means of autopsy reports regardless of cause of death or underlying disease. Inclusion criteria were: patients over 65 years of age. The exclusion criterion was: brains that were fragmented and therefore did not have good conditions to perform the macroscopic and imaging analysis.

\section{Macroscopic analysis of atherosclerosis}

The brains were analysed macroscopically to assess the degree of atherosclerosis of the basilar and the posterior cerebral arteries. The qualitative analysis of atherosclerosis was performed with classification into mild, moderate or severe. The arteries that presented lipid streaks or vessel wall stiffness but did not present lumen narrowing were considered mild atherosclerosis. Moderate atherosclerosis was classified as arteries that showed vessel lumen narrowing of less than $50 \%$ and visible atheroma plaques. The arteries that presented aneurysms, calcifications, or narrowing of more than $50 \%$ and visible atheroma plaques (Figure 1) were classified as severe atherosclerosis.

In the posterior region of the brains, measurements were taken for the inferior temporal gyrus (ITG), the medial temporal occipital gyrus (MTOG), the inferior temporal sulcus (ITS), and the calcarine sulcus (CS) on the left and right sides, using a digital caliper Digital 100.174B (Digimess, São Paulo, SP-Brazil). The location of the measured regions was stan- dardized in all brains. The thickness of the right and left ITG was measured transversely, in the posterior region of the gyrus, near the occipital lobe. (Figure 2A). The width of the right and left ITS was measured transversely at a location just above the ITS measurement (Figure 2B). The left and right MTOG thickness was measured transversely in the medial portion of the gyrus (Figure 2C). The width of CS on the left and right sides was measured transversely and laterally to the MTOG measurement (Figure 2D). Three measurements of the gyrus and sulcus were made and the average of the three calculated. Measurements were recorded in millimetres.

During the macroscopic evaluation, the presence of haemorrhagic foci, infarctions, calcifications and hypotrophy or oedema were also evaluated in all brains.

\section{Acquisition of images}

Through a partnership with the GH-UFTM imaging service, the selected brains were taken for tomographic analysis in the equipment Aqulion 64 (TSX101 A / H) (Toshiba Medical System Corporation, Otawara-Japan), which uses $1 \mathrm{~mm}$ thick slices, with interpolation of $0.5 \mathrm{~mm}$ reconstruction of the images, which increases the quality of reconstruction of the images processed in other planes and even in third dimension.

\section{Processing and interpretation of images}

With the aid of the software RadiAnt DICOM Viewer 3.4.2 (Medixant, Poznan-Poland), the images obtained were analysed and the measurements of the ITG and MTOG and the right and left ITS and CS of each patient were analysed. The ITG was measured in sagittal sections close to the macroscopic measurement (Figure 3A). The ITS was measured in a sagittal section just above the macroscopic measurement of the ITG (Figure 3B). Calcarine sulcus were measured using sagittal sections, at the mid-posterior location just above MTOG (Figure 3C and D). Medial temporal occipital gyrus was measured using axial slices close to the macroscopic measurement (Figure 4 A and B). Three measurements of the gyrus and sulcus were taken and the average of the three calculated. Measurements were recorded in millimetres.

\section{Ethical aspects}

The Human Research Ethics Committee of UFTM approved this research with the CAAE $n^{\circ}$ 59931316600005154. 

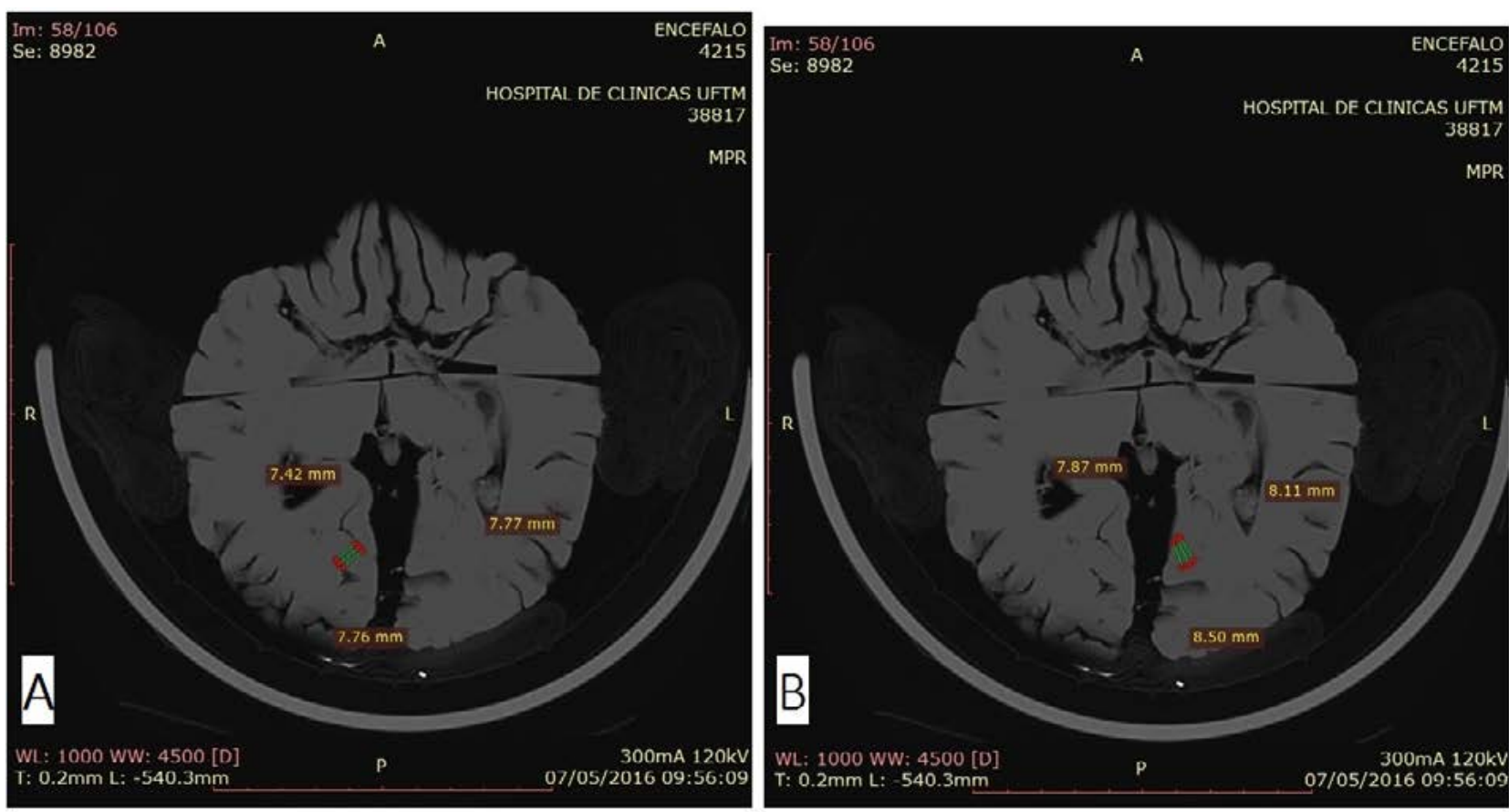

FIGURE 4. Axial sections of encephala. A: Right MTOG measure. B: Left MTOG measure

\section{Statistical analysis}

Prism $^{\circledR}$ (GraphPad Software, San Diego, California-USA) software was used for data analysis. Variable distribution type was verified using the Kolmogorov-Smirnov statistical test. As the result of the distribution of the variables was non-normal, Mann-Whitney U test was used to compare 2 groups, and Kruskal-Wallis test was used to compare 3 or more groups, followed by One way ANOVA (Dunn's test) and by Tukey's test that were used to compare three or more groups. Then, a Spearman correlation coefficient was used. Differences in which the probability $(p)$ was less than $5 \%(p<0.05)$ were considered statistically significant.

\section{RESULTS}

Among the 13 patients evaluated, 6 were men (46.15\%). The ages ranged from 67 to 88 years old, with an average of 73 years old. The body mass index (BMI) of the patients ranged from 18.3 to $43 \mathrm{~kg} / \mathrm{m}^{2}$ with an average of $22.87 \mathrm{~kg} / \mathrm{m}^{2}$. Regarding the basilar artery, 4 patients had mild atherosclerosis (30.8\%), 3 patients had moderate atherosclerosis (23.1\%) and 6 patients had severe atherosclerosis (46.1\%). With respect to the right posterior cerebral artery, 3 patients had mild atherosclerosis (23.1\%), 7 patients had moderate atherosclerosis (53.8\%) and 3 patients had severe atherosclerosis (23.1\%). With respect to the left posterior cerebral artery, 5 patients had mild atherosclerosis (38.5\%), 2 patients had moderate atherosclerosis (15.4\%) and 6 patients had severe atherosclerosis (46.1\%). Cerebral oedema was found in 2 patients and all had cerebral hypotrophy. No areas of haemorrhage or cerebral infarct were observed in the patients. Three patients had aneurysm in the basilar artery, one patient had a cysticercus, and two patients presented encephalic congestion. Thrombi were evidenced in the basilar artery of 1 patient.

There was no statistical difference between the patients with regard to gender and degree of atherosclerosis, or the colour and degree of atherosclerosis in any of the analysed arteries.

Gyrus and sulcus of the posterior brain region presented variation according to the degree of atherosclerosis of the patients. Macroscopically, only CS had a statistically significant difference between the degrees of atherosclerosis in the basilar artery $(\mathrm{p}$ $=0.021$ ), so that patients with mild atherosclerosis (median $=1.827 \mathrm{~mm})$ had sulcus wider than patients with moderate atherosclerosis did (median $=1.203$ $\mathrm{mm}$ ), $\mathrm{H}=7.726$ (Figure 4).

When evaluating CT images, only MTOG exhibited a significant difference between the degrees of atherosclerosis in the basilar artery $(p=0.0156)$, in which patients with mild atherosclerosis (median = $6.838 \mathrm{~mm}$ ) had sulcus wider than patients with severe atherosclerosis did (median $=9.259 \mathrm{~mm})(\mathrm{H}=$ 
5.832). Regarding the right and left posterior cerebral arteries alone, there was no significant difference between the degree of atherosclerosis and the measurements of gyrus or sulcus both macroscopically and in the CT images.

\section{DISCUSSION}

Both methods of analysis presented significant results. Nevertheless, although macroscopically all patients presented clear signs of cerebral hypotrophy, there was a decrease in CS width and an increase in MTOG thickness in patients with a higher degree of atherosclerosis, macroscopically and in tomography, respectively. Macroscopically, there were no signs of brain oedema in most cases. The narrowing of the basilar artery lumen of atherosclerotic cause, in the posterior cerebral arteries and their branches, is the main cause of posterior cerebral hypoperfusion ${ }^{13}$. Patients were expected to present hypotrophy in this region because of hypoxia caused by atherosclerosis. Vascular risk factors such as hypertension and hypercholesterolemia cause damage to the neurovascular unit (NVU) composed of endothelial cells, astrocytes, pericytes, microglia, neurons and circulatory inflammatory cells. The damage in the NVU leads to chronic hypoperfusion, hypoxia, inflammatory activation and oxidative stress ${ }^{14}$.

Although there is a compensatory rearrangement of vessels in an attempt to reduce hypoxia, the blood flow of individuals with hypoperfusion is still lower when compared to individuals with normal perfu$\operatorname{sion}^{15}$. The formation of a hypoxia environment in the NVU contributes to an inflammatory activation that induces the NVU to various adaptations and interactions presenting flow disturbances, angiogenesis, vascular remodelling, loss of junction and adhesion proteins, pericyte retraction, basal membrane disruption, neurovascular decoupling and neuronal impairment. This cascade of events associates injury in the NVU and in the cerebral microcirculation to the tissue damage, which causes neuronal degeneration and cognitive impairment ${ }^{16}$. There is also evidence of foci of gliosis and scars in these individuals ${ }^{15}$.

Gliosis, also called gemioscytic gliosis, is characterized by the hypertrophy and hyperplasia of astrocytes activated by inflammatory signs following a tissue injury of any type, such as hypoxia, the presence of tumours and traumas ${ }^{17}$. It can be identified microscopically, but macroscopically there is no obvious sign. However, in the present study, the increase in the thickness of the gyrus, which could only be detected with the digital caliper and with the tomographic image analysis software, may be a sign of the occurrence of gliosis in these cases of more severe atherosclerosis. Changes in white brain matter are also factors that indicate risk of cerebrovascular events, stroke, cognitive impairment, or dementia, and death ${ }^{18}$. Meanwhile, in the present study, this factor was not evaluated because brains formalin-fixed for a long time lose the ability to demonstrate areas of hyperdensity, calcifications or haemorrhages at the CT examination (personal communication).

There is evidence in experimental models that in mice with astrocyte reduction in white brain matter and in the presence of inflammation, there is axonal degeneration, demyelination and gliosis, as well as cognitive deficit. This suggests that astrocytes are involved in the pathophysiology of VCI and that anti-inflammatory interventions can bring beneficial effect ${ }^{19}$. Karen Horsburgh discussed the contribution of microglial proliferation to axon-glial disruption and impairment of white matter function in an experimental model of VCI. Studies like these support that, in situations of inflammation, the NVU reacts with diverse pathological responses, including gliosis, which may temporarily increase the size of the affected tissue $\mathrm{e}^{20}$.

Our patients were expected to have a high degree of atherosclerosis because of the average age of the group, 67 years old. Thus, it is probable that most of them presented a condition of brain hypoperfusion in the posterior region of the encephalon due to the narrowing of the lumen of the posterior and the basilar cerebral arteries. VCI is not synonymous with dementia but it is used to describe an intermediate stage between normal cognition and vascular-caused dementia with the presence of mild cognitive impairment $^{21}$. Dementia affects $7 \%$ of the population over 65 years old, and $30 \%$ of people over 80 years old ${ }^{22}$. In addition, it is now recognized that vascular diseases lead to dementia ${ }^{23}$. There is also close relationship between vascular dementia and Alzheimer's disease as common risk factors: systemic hypertension ${ }^{24}$, diabetes, smoking ${ }^{25}$ and hypercholesterolemia ${ }^{26}$.

Vascular cognitive impairment encompasses individuals who have stroke-related cognitive impairment, multiple cortical or subcortical infarcts, silent infarcts, small vessel disease with white matter lesion and lacunae $^{3}$. Criteria for identifying VCI should still be better established. Symptoms may vary depending on the 
location of the infarcts, for example. Nonetheless, subcortical ischemia often leads to attention deficit and executive dysfunction, with slow motor development and slowness in processing information. Episodic memory is not as apparent as in Alzheimer's disease. Psychiatric symptoms are as common and important as in Alzheimer's disease, and mood swings such as depression, emotional instability and apathy are frequent and persistent ${ }^{27}$. Until this moment, this group of researchers did not conduct a survey of the diagnosis or symptom of some type of cognitive impairment in our patients, which does not allow us to establish a direct relationship between symptoms and macroscopic or imaging findings.

\section{CONCLUSIONS}

This study demonstrated that it is possible to establish a post-mortem parameter of thickness measurements of gyrus and sulcus according to the degree of atherosclerosis of patients. Thus, in vivo, monitoring the thickness of the patient's gyrus and sulcus may provide information on the increase or decrease of gyrus and sulcus, and thus prevent future complications, such as VCI.

\section{ACKNOWLEDGMENTS}

The authors are grateful to the professionals of the Laboratory of Histopathology, and Professor Silvia Azevedo Terra of the Discipline of General Pathology of the Federal University of Triângulo Mineiro, Uberaba, Minas Gerais, Brasil.

\section{CONFLICT OF INTEREST}

On behalf of all authors, the corresponding author states that there is no conflict of interest.

\section{RESUMO}

INTRODUÇão E OBJETIVO: A aterosclerose cerebral é a principal causa de lesões que contribuem para o comprometimento cognitivo vascular (CCV) e demência vascular, seguida da arteriosclerose de pequenos vasos e da angiopatia amiloide cerebral. Sendo assim, este estudo comparou as alterações radiológicas post mortem de adultos autopsiados com as alterações macroscópicas na região posterior desses encéfalos a fim de estabelecer uma relação entre as duas formas de análise e discutir sobre a relevância da prevenção do CCV em pacientes com aterosclerose encefálica.

MATERIAL E MÉTODOS: Treze encéfalos foram analisados macroscopicamente para avaliar o grau de aterosclerose das artérias basilar e cerebral posterior. Os pacientes foram autopsiados na disciplina de Patologia Geral no HC-UFTM em Uberaba, Minas Gerais, Brasil. A análise qualitativa da aterosclerose foi realizada com as classificações discreta, moderada ou acentuada. A espessura dos giros e a largura dos sulcos na região posterior dos encéfalos foram analisadas macroscopicamente e por tomografia computadorizada.

RESULTADOS E CONCLUSÃo: Houve diminuição na largura do sulco calcarino e aumento na espessura do giro occipital temporal medial de acordo com o aumento do grau de aterosclerose macroscopicamente e por tomografia, respectivamente. A baixa oxigenação causada pela aterosclerose provoca a inflamação do parênquima encefálico, provavelmente levando à hipertrofia das células da micróglia e ao consequente aumento dos giros e estreitamento dos sulcos, como observado no presente estudo.

PALAVRAS-CHAVE: Arteriosclerose intracraniana. Disfunção cognitiva. Transtornos cerebrovasculares. Transtornos cognitivos. Tomografia computadorizada por raios $X$.

\section{REFERENCES}

1. Thal DR, Grinberg LT, Attems |. Vascular dementia: different forms of vessel disorders contribute to the development of dementia in the elderly brain. Exp Gerontol. 2012;47(11):816-24.

2. Ravensbergen J, Ravensbergen JW, Krijger JK, Hillen B, Hoogstraten $\mathrm{HW}$. Localizing role of hemodynamics in atherosclerosis in several human vertebrobasilar junction geometries. Arterioscler Thromb Vasc Biol. 1998;18(5):708-16.

3. O'Brien JT, Erkinjuntti T, Reisberg B, Roman G, Sawada T, Pantoni L, et al. Vascular cognitive impairment. Lancet Neurol. 2003;2(2):89-98.

4. Ferrer I. Cognitive impairment of vascular origin: neuropathology of cognitive impairment of vascular origin. J Neurol Sci. 2010;299(1-2):139-49.

5. Grinberg LT, Thal DR. Vascular pathology in the aged human brain. Acta Neuropathol. 2010;119(3):277-90.

6. Koc ZP, Balci TA, Akarsu S, Unal K. The role of positron emission tomography/CT in hypoxic ischaemic encephalopathy in children. BMJ Case Rep. 2013;2013. pii: bcr0320126001.
7. Wake-Buck AK, Gatenby JC, Gore IC. Hemodynamic characteristics of the vertebrobasilar system analysed using MRI-based models. PLoS One. 2012;7(12):e51346.

8. Mokrane FZ, Savall F, Rérolle C, Blanc A, Saint Martin P, Rousseau H, et al. The usefulness of post-mortem CT angiography in injuries caused by falling from considerable heights: three fatal cases. Diagn Interv Imaging. 2014;95(11):1085-90.

9. Robert IS, Benamore RE, Benbow EW, Lee SH, Harris JN, Jackson A, et al. Post-mortem imaging as an alternative to autopsy in the diagnosis of adult deaths: a validation study. Lancet. 2012;379(9811):136-42.

10. Dedouit F, Otal P, Costagliola R, Loubes Lacroix F, Telmon N, Rouge D, et al. Role of modern cross-sectional imaging thanatology: a pictorial essay. J Radiol. 2006;87(6 Pt 1):619-38.

11. Grabherr S, Doenz F, Steger B, Dirnhofer R, Dominguez A, Sollberger B, et al. Multi-phase post-mortem CT angiography: development of a standardized protocol. Int J Legal Med. 2011;125(6):791-802. 
12. Palmiere C, Binaghi S, Doenz F, Bize P, Chevallier C, Mangin P, et al. Detection of haemorrhage source: the diagnostic value of post-mortem CT-angiography. Forensic Sci Int. 2012;222(1-3):33-9.

13. Voetsch B, DeWitt LD, Pessin MS, Caplan LR. Basilar artery occlusive disease in the New England Medical Center Posterior Circulation Registry. Arch Neurol. 2004;61(4):496-504

14. Stanimirovic DB, Friedman A. Pathophysiology of the neurovascular unit: disease cause or consequence? I Cereb Blood Flow Metab. 2012;32(7):1207-21.

15. Boehm-Sturm P, Füchtemeier M, Foddis M, Mueller S, Trueman RC, Zille $M$, et al. Neuroimaging biomarkers predict brain structural connectivity change in a mouse model of vascular cognitive impairment. Stroke. 2017;48(2):468-75

16. Zlokovic BV. Neurovascular pathways to neurodegeneration in Alzheimer's disease and other disorders. Nat Rev Neurosci. 2011;12(12):723-38.

17. Latov N, Nilaver G, Zimmerman EA, Johnson WG, Silverman AJ, Defendini $\mathrm{R}$, et al. Fibrillary astrocytes proliferate in response to brain injury: a study combining immunoperoxidase technique for glial fibrillary acidic protein and radioautography of tritiated thymidine. Dev Biol. 1979;72(2):381-4.

18. Debette S, Markus HS. The clinical importance of white matter hyperintensities on brain magnetic resonance imaging: systematic review and meta-analysis. BMI. 2010;341:c3666.

19. Delekate A, Füchtemeier M, Schumacher T, Ulbrich C, Foddis M, Petzold GC. Metabotropic P2Y1 receptor signaling mediates astrocytic hyperactivity in vivo in an Alzheimer's disease mouse model. Nat Commun. 2014:5:5422.

20. Demuth HU, Dijkhuizen RM, Farr TD, Gelderblom M, Horsburgh K, lade- cola $\mathrm{C}$, et al. Recent progress in translational research on neurovascular and neurodegenerative disorders. Restor Neurol Neurosci. 2017;35(1):87-103.

21. Consoli A, Pasi M, Pantoni L. Vascular mild cognitive impairment: concept, definition, and directions for future studies. Aging Clin Exp Res. 2012;24(2):113-6.

22. Lobo A, Launer L), Fratiglioni L, Andersen K, Di Carlo A, Breteler MM, et al. Prevalence of dementia and major subtypes in Europe: a collaborative study of population-based cohorts. Neurologic Diseases in the Elderly Research Group. Neurology. 2000;54(1 Suppl 5):S4-9.

23. Ballard C, McKeith I, O'Brien J, Kalaria R, Jaros E, Ince P, et al. Neuropathological substrates of dementia and depression in vascular dementia, with a particular focus on cases with small infarct volumes. Dement Geriatr Cogn Disord. 2000;11(2):59-65.

24. Román GC, Tatemichi TK, Erkinjuntti T, Cummings JL, Masdeu JC, Garcia $\mathrm{H}$, et al. Vascular dementia: diagnostic criteria for research studies. Report of the NINDS-AIREN International Workshop. Neurology. 1993;43(2):250-60.

25. Ott A, Stolk RP, van Harskamp F, Pols HA, Hofman A, Breteler MM. Diabetes mellitus and the risk of dementia: The Rotterdam Study. Neurology. 1999;53(9):1937-42

26. Rockwood K, Kirkland S, Hogan DB, MacKnight C, Merry H, Verreault R, et al. Use of lipid-lowering agents, indication bias, and the risk of dementia in community-dwelling elderly people. Arch Neurol. 2002;59(2):223-7.

27. Erkinjuntti T, Kurz A, Gauthier S, Bullock R, Lilienfield S, Damaraju CV. Efficacy of galantamine in probable vascular dementia and Alzheimer's disease combined with cerebrovascular disease: a randomised trial. Lancet. 2002;359(9314):1283-90. 